Pensamiento Crítico Vol. 21, № 2, pp. 83 - 103

\title{
La actividad empresarial del Estado: Entre la subsidiariedad y el trato legal igualitario
}

State-owned enterprises: Between subsidiarity and equal legal treatment

[Recepción: Setiembre de 2016 / Conformidad: Octubre de 2016]

Gustavo Galván Pareja ${ }^{1}$

\section{RESUMEN}

La Constitución peruana establece limitaciones al desarrollo de la actividad empresarial del Estado y, a fin de eliminar ventajas y privilegios, establece un mismo tratamiento legal para empresas públicas y no públicas. En este artículo se analizan las normas constitucionales sobre la actividad empresarial del Estado y tres supuestos en los que la legislación establece un trato diferenciado para la actividad empresarial pública y privada.

Palabras clave: Derecho constitucional económico, empresas estatales, competencia desleal.

\section{ABSTRACT}

The Peruvian Constitution provides restrictions on the development of the stateowned enterprises and, in order to eliminate advantages and privileges, establishes

1 Abogado por la Universidad Nacional Mayor de San Marcos, magíster en Derecho (DEA en Derecho de los Negocios por la Universidad París XIII), profesor de Derecho Económico de la Facultad de Ciencias Económicas de la Universidad Nacional Mayor de San Marcos. 


\section{Pensamiento Crítico Vol. Zl, No 2}

equal legal treatment for state-owned and private companies. This article describes the constitutional regulation of state-owned enterprises and three cases in which the law provides a different legal treatment for private and state-owned companies.

Keywords: Constitutional law, public enterprises, unfair competition.

\section{Introducción}

La Constitución de 1993 estableció un marco económico claramente diferenciado respecto de la Constitución de 1979. Esta última, heredera del estado de bienestar europeo, concebía a la economía social de mercado como un régimen económico en el cual el desenvolvimiento de la actividad privada convivía con un amplio espacio para la intervención estatal. La Constitución de 1993, por el contrario, procuró establecer un marco económico facilitador del desarrollo de la actividad económica privada con una limitada intervención estatal. Con este propósito, no solo se establecieron las reglas básicas de un marco económico fundado en el funcionamiento del mercado libre, sino que se diseñaron mecanismos para impedir que los sucesivos gobiernos pudiesen discurrir por las mismas rutas que los gobiernos de las décadas anteriores a los años 1990 habían transitado ${ }^{2}$. El contexto histórico tanto nacional como internacional en el que se aprobó la Constitución de 1993 tuvo, sin duda, un rol importante en las decisiones que se adoptaron en ese momento, al concebir como única vía para el desarrollo económico la apertura del mercado y la reducción del aparato estatal ${ }^{3}$.

Habiendo transcurrido más de veinte años de vigencia de la Constitución de 1993, entre los temas que son materia de continua discusión se encuentra el papel que debe desempeñar el Estado en la economía y los alcances de su intervención. De manera particular, se discute en qué medida o circunstancia el Estado puede o debe realizar actividad empresarial. Por ello, no nos debe extrañar que en el debate político se plantee

2 De allí que García (1998, Tomo II, p. 117) se refiera a la Constitución de 1993 como una Constitución económica "rígida", en la medida que se establecen reglas cerradas y exentas de matices sobre la materia. La opción por un modelo-programa es obligatoriamente aplicada a todos los gobiernos de un Estado.

3 Recordemos que la década de 1990 estuvo marcada a nivel internacional por la desaparición de la Unión Soviética y, con ella, del mundo bipolar que nació de las cenizas de las Segunda Guerra Mundial. De otro lado, América Latina recibió la influencia y aplicó, en mayor o menor medida, las recomendaciones del Consenso de Washington, que planteaba una reducción del aparato estatal y la implementación de medidas para la liberalización de las economías. 


\section{Gustavo Galván Pareja}

continuamente, desde diversos sectores, la modificación de la Constitución en materia económica como un requisito para implementar reformas.

Al lado de disposiciones constitucionales dirigidas a resguardar libertades económicas y a otorgar garantías a la inversión privada frente a la intervención estatal, ${ }^{4}$ la Constitución se ocupa en el artículo $60^{\circ}$ de la regulación de la actividad empresarial del Estado. En los párrafos segundo y tercero, establece lo siguiente:

"Sólo autorizado por ley expresa, el Estado puede realizar subsidiariamente actividad empresarial, directa o indirecta, por razón de alto interés público o manifiesta conveniencia nacional.

La actividad empresarial, pública o no pública, recibe el mismo tratamiento legal."

En este artículo desarrollaremos primero el concepto de subsidiariedad, entre otros aspectos del marco constitucional y legal que rige la actividad empresarial del Estado y, en segundo lugar, los alcances del trato legal igualitario que dispone el artículo $60^{\circ}$ de la Constitución. Al desarrollar este último punto, analizaremos tres situaciones en las cuales se establece un trato legal diferenciado para la actividad pública y no pública sin una justificación consistente. En particular, nos concentraremos en el acto de competencia desleal denominado "violación de normas" que nos permitirá aplicar los conceptos previos de subsidiariedad y trato igualitario.

\section{La subsidiariedad de la actividad empresarial del Estado}

El segundo párrafo del artículo $60^{\circ}$ de la Constitución aborda la subsidiariedad de la actividad empresarial del Estado, tema que ha sido y es ampliamente discutido, así como su relación con los conceptos fundamentales de la economía social de mercado.

El concepto de subsidiariedad no se ciñe únicamente a la actividad empresarial del Estado. Por el contrario, constituye un principio de carácter general que tiene una de sus expresiones en los alcances y limitaciones a la actividad empresarial del Estado.

4 Algunas de ellas: la incorporación de los contratos-ley y la llamada "intangibilidad de los contratos" (artículo $62^{\circ}$ ), restricciones mayores a la expropiación (artículo $70^{\circ}$ ), igualdad de trato a la inversión nacional y extranjera (artículo $63^{\circ}$ ). 


\section{Pensamiento Crítico Vol. ᄅl, № 2}

Sobre esta materia, el Tribunal Constitucional se ha pronunciado en los siguientes términos:

“4.6 La actuación subsidiaria del Estado en la economía.

19. Este principio puede concebirse en dos sentidos: vertical y horizontal.

La subsidiariedad vertical se refiere a la relación existente entre un ordenamiento mayor-que puede ser una organización nacional o central-y un ordenamiento menor -que pueden ser las organizaciones locales o regionales-, según la cual el primero de ellos sólo puede intervenir en aquellos ámbitos que no son de competencia del ordenamiento menor. Dicha orientación guarda estrecha relación con los servicios públicos y el desarrollo económico-social.

Por su parte, la subsidiariedad horizontal está referida a la relación existente entre el Estado y la ciudadanía, en la cual el cuerpo político, respetando la autonomía y la libre determinación de los individuos, reduce la intervención pública a lo esencial.

A través de ambos sentidos, el principio de subsidiariedad se constituye en un elemento de vital importancia para el Estado democrático de derecho, ubicándose entre la esfera de la descentralización institucional y la autonomía de lo social, en cuanto principio que inspira un proceso de socialización de los poderes públicos. Consecuentemente, el principio de subsidiariedad surge en el constitucionalismo moderno como una técnica decididamente útil para lograr la pacificación social o la resolución de los conflictos mediante el respeto absoluto de los derechos y libertades individuales, y tiene como fin la reestructuración del equilibrio entre lo público y lo privado según una adecuada flexibilización que acentúa la concepción democrática del ordenamiento estatal" ${ }^{5}$.

Respecto a la subsidiariedad horizontal, cuando el Tribunal Constitucional se refiere a reducir la intervención pública "a lo esencial" no debe entenderse que el Estado debe reducirse al mínimo, menos aún convertirse en un Estado ausente. Todo lo contrario; su actuación en materia económica debe desplegarse en aras de alcanzar el bien común ${ }^{6}$.

5 Sentencia del Tribunal Constitucional de fecha 11 de noviembre de 2003 (Exp. № 0008-2003-AI/TC).

6 Kresalja (2015) nos refiere a Germán Bidart Campos (1999, p. 120) al señalar que "... librar a las fuerzas de los particulares el juego total de las relaciones económicas sin presencia del Estado no condice con el significado del principio de subsidiariedad". 


\section{Gustavo Galván Pareja}

Al respecto, en la sentencia precitada del Tribunal Constitucional se precisa que

"21. Sin perjuicio de lo expuesto, debe quedar claro que, aunque se postule el respeto de las libertades de los individuos y de los grupos, el principio de subsidiariedad no pone en discusión el papel y la importancia del Estado; por el contrario, se orienta a valorarlo, procediendo a una redefinición y a una racionalización de los roles en la dinámica de las relaciones entre el Estado y los ciudadanos, entre lo público y lo privado.

Desde la perspectiva de una organización social inspirada en el principio de subsidiariedad, el Estado emerge como garante final del interés general, desde el momento en que su tarea consiste en la intervención directa para satisfacer una necesidad real de la sociedad, cuando la colectividad y los grupos sociales, a los cuales corresponde en primer lugar la labor de intervenir, no están en condiciones de hacerlo".

De otro lado, es importante resaltar que el concepto de subsidiariedad no solo se aplica en materia económica. Como señala Ariño (2004, p. 112), la exigencia de libertad, condición necesaria para el pleno desarrollo de la personalidad y para el ejercicio de la creatividad humana, es el fundamento último del principio de subsidiariedad, “... que no se refiere sólo al ámbito económico, sino sobre todo, muy esencialmente, a los ámbitos educativo, cultural, artístico e intelectual, porque estos son los grandes espacios de la creatividad humana"?.

Las disposiciones de la Constitución de 1993, junto con otras normas legales de la época, conformaron el soporte legal del proceso de privatización de las empresas del Estado que se desarrolló durante la década de 1990 y hasta inicios de la década del 2000. Cuando el proceso de privatización se agotó, debido a los cuestionamientos y oposición que generó su desarrollo y sus consecuencias, se plantearon otras formas de participación privada en las empresas del Estado, tales como mecanismos de asociación o la incorporación de accionistas privados.

La persistencia de la actividad empresarial del Estado hizo necesario enfatizar en las disposiciones legales sobre la materia que las empresas estatales debían subsistir guiadas por criterios de eficiencia económica y desenvolverse en un marco de autonomía, aun cuando sin ir más allá de los límites definidos por el principio de subsidiariedad constitucional.

$7 \quad$ En el mismo sentido se pronuncia Kresalja (2015, p. 39). 


\section{Pensamiento Crítico Vol. ᄅl, № 2}

Esta orientación se expresa con claridad en el Decreto Legislativo N 1031 -"Decreto Legislativo que promueve la eficiencia de la actividad empresarial del Estado"8- que establece en su artículo $1^{\circ}$ lo siguiente:

"El presente Decreto Legislativo tiene por objeto promover la eficiencia de la Actividad Empresarial del Estado, principalmente en lo que se refiere a sus principios, naturaleza, organización, conducción, funciones, gestión, recursos y su vinculación con los Sistemas Administrativos del Estado.

Para tal efecto, se establece disposiciones que buscan promover una gestión eficiente y autónoma y un sistema de control adecuado, en un contexto de transparencia".

A su vez, las disposiciones legales más recientes -más allá de aquellas que en su momento tenían como objetivo desarrollar los procesos de privatización- se orientan ahora a facilitar una eventual participación de inversionistas privados en las empresas estatales. Una expresión de ello son las disposiciones contenidas en el artículo $12^{\circ}$ del Decreto Legislativo $\mathrm{N}^{\circ} 1031^{9}$ o en el artículo $3^{\circ}$ de la Ley $\mathrm{N}^{\circ} 30130^{10}$, ambas relativas a la incorporación de capital privado en empresas del Estado a través del mercado de valores.

Esta orientación general de la legislación sobre las empresas del Estado ha convivido con otras leyes que han establecido disposiciones específicas sobre algunas de ellas, procurando reforzarlas o encargarles actividades puntuales alineadas con las políticas del sector al que pertenecen ${ }^{11}$. Estas normas fueron promovidas generalmente por sectores de la política interesados en impulsar un rol más activo del Estado en la economía o con el objeto de que el Estado atienda requerimientos de la población a través de las empresas de su propiedad. Es necesario tener presente que las empresas

$8 \quad$ Publicado en el Diario Oficial El Peruano el 24 de junio del 2008.

9 El artículo $12^{\circ}$ dispone que por acuerdo del Directorio de FONAFE se determinará las Empresas del Estado que deben inscribir un mínimo de $20 \%$ de su capital social en el Registro Público del Mercado de Valores.

10 La ley $N^{\circ} 30130$, aplicable a Petroperú S.A., autoriza en el artículo $3^{\circ}$ a la venta o emisión de acciones para que sean colocadas a través del mercado de valores.

11 Algunos ejemplos a citar son la Ley № 29970 que afianza la seguridad energética y promueve el desarrollo de polo petroquímico en el sur del país y que establece la participación de Petroperú y Electroperú en proyectos de seguridad energética; la Ley $\mathrm{N}^{\circ} 28840$, Ley de fortalecimiento y modernización de Petroperú; la Ley No 29969 que faculta a las empresas de distribución de electricidad de propiedad del Estado, a ejecutar programas de masificación de gas natural. De otro lado, continuamente se presentan y debaten proyectos de ley para la modernización o fortalecimiento de empresas del Estado como Sedapal o la Empresa Nacional de Puertos del Perú - Enapu. 


\section{Gustavo Galván Pareja}

estatales deben contribuir a que el Estado pueda alcanzar sus fines, por lo que no es ajeno a su buen funcionamiento que asuman encargos específicos, tal como se encuentra previsto en el artículo $5^{\circ}$ del Decreto Legislativo $\mathrm{N}^{\circ} 1031^{12}$.

A la convivencia de un conjunto de normas sobre la actividad empresarial del Estado, orientadas a la búsqueda de autonomía y eficiencia económica, en el marco de la subsidiariedad, con otras que procuran promover una mayor actividad empresarial estatal en diversos ámbitos, debemos agregar que existen normas específicas para empresas que operan en el ámbito municipal, así como disposiciones que autorizan a entidades del Estado a realizar actividad empresarial (por ejemplo, las universidades públicas a través de los centros de producción).

En estos últimos casos, la normatividad que autoriza estas actividades suele estar ligada al cumplimiento de los fines institucionales de las entidades que desarrollan la actividad empresarial. Sin embargo, la producción de bienes o prestación de servicios a la comunidad se encuentra también concebida como una forma de obtener ingresos mayores que se sumen a los que el presupuesto general de la república otorga a la entidad. Un ejemplo palpable de ello se encuentra en los centros de producción de las universidades estatales que producen bienes y prestan servicios para el mercado, contribuyendo a financiar el presupuesto universitario.

\section{Empresas del Estado y otras entidades que desarrollan actividad empre- sarial}

La actividad empresarial del Estado se desarrolla, en parte, a través de sus empresas organizadas bajo esquemas similares a los de las organizaciones privadas. Con excepción de las empresas con potestades públicas, las empresas del Estado asumen en forma de sociedad anónima, siendo el Estado el titular de la mayoría o la totalidad de las acciones.

12 El numeral 5.2 del artículo $5^{\circ}$ señala que "Las Empresas del Estado sólo podrán recibir encargos especiales, mediante mandato expreso, aprobado por Decreto Supremo refrendado por el Ministro de Economía y Finanzas y con el voto aprobatorio del Consejo de Ministros. En este caso, las Empresas del Estado deberán ser provistas de los recursos necesarios para su sostenibilidad financiera, debiendo registrarse dichos encargados en una contabilidad separada, y revelarlos adecuadamente en sus estados financieros. Cuando los encargos especiales califiquen como proyectos de inversión pública, para que éstos puedan ser ejecutados por las Empresas del Estado, deberán contar previamente con las evaluaciones correspondientes dentro del marco del Sistema Nacional de Inversión Pública." 


\section{Pensamiento Crítico Vol. ᄅl, № 2}

El Decreto Legislativo $N^{\circ} 1031$ señala en el artículo $4^{\circ}$ que la actividad empresarial del Estado se desarrolla bajo alguna de las siguientes formas:

"4.1 Empresas del Estado de accionariado único: Empresas organizadas bajo la forma de sociedades anónimas en las que el Estado ostenta la propiedad total de las acciones y, por tanto, ejerce el control íntegro de su Junta General de Accionistas.

4.2 Empresas del Estado con accionariado privado: Empresas organizadas bajo la forma de sociedades anónimas, en las que el Estado ostenta la propiedad mayoritaria de las acciones y, por tanto, ejerce el control mayoritario de su Junta General de Accionistas, existiendo accionistas minoritarios no vinculados al Estado.

4.3 Empresas del Estado con potestades públicas: Empresas de propiedad estatal cuya ley de creación les otorga potestades de derecho público para el ejercicio de sus funciones. Se organizan bajo la forma que disponga su ley de creación.

El accionariado estatal minoritario en empresas privadas no constituye Actividad Empresarial del Estado y se sujeta a las disposiciones de la Ley General de Sociedades y demás normas aplicables a tales empresas".

Es importante precisar que el Decreto Legislativo $\mathrm{N}^{\circ} 1031$ solo se aplica a las empresas del Estado bajo el ámbito del Fondo Nacional de Financiamiento de la Actividad Empresarial del Estado - FONAFE. Este fondo es una empresa de derecho público adscrita al Ministerio de Economía y Finanzas. Otras empresas del Estado cuentan con regímenes particulares, como es el caso de Petróleos del Perú -Petroperú S.A. o las empresas municipales.

En adición a ello, cualquier entidad del Estado podría realizar actividades de prestación de servicios o de producción de bienes para la comunidad, que conviven y eventualmente concurren con las actividades del sector privado. Algunos ejemplos de ello son las prestaciones de servicios de hospitales, municipalidades, universidades nacionales (tanto a través de su servicio educativo como mediante sus centros de producción), etc. La determinación del carácter empresarial de algunas actividades en situaciones específicas requiere un análisis previo orientado a determinar si la actividad desarrollada por la entidad pública es de carácter empresarial o si se trata de actividades que pueden desarrollarse en el marco de sus fines y funciones. 


\section{Gustavo Galván Pareja}

Al respecto, el Instituto Nacional de Defensa de la Competencia y de la Protección de la Propiedad Intelectual - Indecopi ha tenido la oportunidad de pronunciarse, en diversas resoluciones, sobre el carácter empresarial de actividades desplegadas por entidades del sector público.

En la Resolución $N^{\circ}$ 3134-2010/SC1-Indecopi, de fecha 29 de noviembre de $2010^{13}$, la Sala de Defensa de la Competencia N ${ }^{\circ} 1$ indicó que la limitación a la actividad empresarial del Estado establecida en el principio de subsidiariedad estatal...

“... se aplica a toda actuación estatal que consista en la producción, distribución, desarrollo o intercambio de productos o servicios de cualquier índole, con independencia de la existencia o no de ánimo lucrativo y de la forma jurídica que adopte el Estado para prestar el bien o servicio. No constituye actividad empresarial y se excluye de la limitación constitucional el ejercicio de potestades de ius imperium y la prestación de servicios asistenciales".

En la misma resolución, Indecopi desarrolló el alcance del ejercicio de potestades de ius imperium y prestación de servicios asistenciales, entre otros aspectos de interés que, por el momento, no desarrollaremos ${ }^{14}$.

\section{Igualdad en el tratamiento legal de la actividad empresarial pública y privada}

El tercer párrafo del artículo $60^{\circ}$ de la Constitución señala que "la actividad empresarial, pública o no pública, recibe el mismo tratamiento legal", con lo cual se establece un régimen de igualdad en el tratamiento legal de la actividad empresarial.

13 Expediente $\mathrm{N}^{\circ}$ 201-2008/CCD, denuncia presentada por Pollería El Rancho II E.I.R.L. contra la Universidad del Altiplano - Puno sobre competencia desleal.

14 Al respecto, puede revisarse los numerales 38 a 46 de la Resolución No 3134-2010/SC1-INDECOPI. Eduardo Quintana ("El rol asistencial y subsidiario de la actividad empresarial del Estado y su alto interés público o manifiesta conveniencia nacional" En: Diálogo con la jurisprudencia № 149, 2011, p. 29-33), citado por Kresalja (2015, p. 171), considera que si las prestaciones son de carácter asistencial podrían ser válidamente canalizadas a través de la actividad empresarial del Estado, pues cumplirían con tener carácter subsidiario y, en consecuencia, no existe razón para excluirlas del examen de los requerimientos del artículo $60^{\circ}$ de la Constitución. Atendiendo a una preocupación distinta, Diez Canseco y Buleje (2011, p. 233) opinan que al excluirse los servicios asistenciales del análisis de subsidiariedad, podría haberse abierto una puerta a través de la cual las entidades del Estado evadan el control de la Ley de Represión de Competencia Desleal. 


\section{Pensamiento Crítico Vol. ᄅl, № 2}

Esta disposición se planteó en su momento para eliminar las ventajas o privilegios con los que contaba la actividad empresarial estatal, así como para remarcar que la subsistencia de las empresas del Estado debía estar ligada a un desempeño empresarial y económico que les otorgue viabilidad antes que a favoritismos o ventajas derivadas de la propiedad estatal.

En aplicación del tercer párrafo del artículo $60^{\circ}$, las empresas del Estado tributan tal cual lo hace el sector privado, aplican a sus trabajadores regímenes laborales propios del sector privado y están sujetas a las mismas normas regulatorias que cualquier empresa privada. El carácter estatal de la empresa no las exime de tramitar los permisos o autorizaciones que las empresas privadas requieren, ni las libera de los controles y supervisiones de los organismos estatales que verifican el cumplimiento de normas sectoriales.

Sin embargo, esta disposición debe leerse también en el sentido de que el sector privado no debe gozar de un trato ventajoso respecto de la actividad empresarial del Estado y que esta última no debe afrontar restricciones, limitaciones o condiciones más onerosas que las que enfrenta la empresa privada para su desarrollo. Las limitaciones o las restricciones solo deben fundamentarse en el carácter subsidiario de la actividad empresarial del Estado, previsto en el segundo párrafo del artículo $60^{\circ}$ de la Constitución.

Asimismo, es importante dejar sentado que el "mismo tratamiento legal" para la actividad empresarial pública y no pública no significa "trato idéntico". En efecto, siempre es posible que la legislación establezca diferencias justificadas por la naturaleza de las cosas que no representen un tratamiento arbitrario.

Ello se evidencia, por ejemplo, en las disposiciones legales sobre contrataciones del Estado. Las empresas estatales y demás entidades del Estado deben realizar sus contrataciones (compras, contratos de servicios, etc.) siguiendo procesos generalmente lentos, que no solamente acarrean gastos de personal y demoras, sino que, en ocasiones, se frustran sin alcanzar su objetivo. De igual modo, las entidades del Estado afrontan gastos derivados de la supervisión que ejerce la Contraloría General de la República, toda vez que deben asignar personal a la atención de requerimientos y documentar especialmente todas sus decisiones, a fin de poderlas justificar cuando se necesite. Si bien en estos supuestos, y en otros más, las entidades del Estado que realizan actividad 


\section{Gustavo Galván Pareja}

empresarial se encuentran ante un tratamiento legal diferenciado que puede resultar oneroso y que las lleva a una situación de desventaja frente al sector privado, este tratamiento se encuentra justificado en la medida que sus actividades involucran recursos del Estado que deben ser adecuadamente resguardados. El control y la supervisión del uso de los recursos por estas empresas puede variar en su forma e intensidad, sobre todo, a fin de no entorpecer innecesariamente el desarrollo de sus actividades; sin embargo, en este caso, el tratamiento diferenciado se encuentra justificado y no vulnera las disposiciones constitucionales.

De lo expresado en los párrafos anteriores se colige que, en caso encontremos en la legislación un trato diferente entre la actividad empresarial pública y no pública, este tratamiento deberá contar con una justificación suficiente. De no ser así, la norma legal en cuestión no se encontraría alineada con las disposiciones constitucionales.

A continuación, llevaremos esta línea de análisis a las disposiciones sobre competencia desleal relacionadas con la actividad empresarial del Estado y a la revisión de otras dos normas que establecen un trato diferenciado entre la actividad empresarial pública y no pública.

\subsection{La actividad empresarial no subsidiaria del Estado como acto de competencia desleal}

A partir del año 2008, la legislación sobre competencia desleal se encuentra contenida en el Decreto Legislativo No 1044 - "Ley de Represión de la Competencia Desleal" (en adelante LRCD). En ella se establece como una modalidad de competencia desleal los actos de "violación de normas", infracción consistente en

“... la realización de actos que tengan como efecto, real o potencial, valerse en el mercado de una ventaja significativa derivada de la concurrencia en el mercado mediante la infracción de normas imperativas. A fin de determinar la existencia de una ventaja significativa se evaluará la mejor posición competitiva obtenida mediante la infracción de normas." (artículo14", numeral 14.1).

Como puede apreciarse, un requisito para la comisión de la infracción es contar con una ventaja significativa, derivada de la concurrencia mediante la infracción de normas. 


\section{Pensamiento Crítico Vol. ᄅl, № 2}

Este acto de competencia desleal, se encontraba previsto en la normatividad previa a la $\mathrm{LRCD}$, considerando también necesaria la existencia de una ventaja significativa para que se configure la infracción ${ }^{15}$.

Adicionalmente, la LRCD incorporó un supuesto no contemplado en la legislación precedente:

"14.3.- La actividad empresarial desarrollada por una entidad pública o empresa estatal con infracción al artículo $60^{\circ}$ de la Constitución Política del Perú configura un acto de violación de normas que será determinado por las autoridades que aplican la presente Ley. En este caso, no se requerirá acreditar la adquisición de una ventaja significativa por quien desarrolle dicha actividad empresarial"'(las negritas son nuestras). ${ }^{15}$

De este modo, la norma introduce la presunción de que toda violación al artículo $60^{\circ}$ de la Constitución acarrea una ventaja significativa que no requiere ser probada, es decir, establece una presunción solo aplicable a la actividad empresarial del Estado.

Esta presunción no se basa en aspectos objetivos de la actividad realizada que nos permitan inferir que existe una ventaja significativa que no requiere ser demostrada o que es evidente en sí, sino que se fundamenta en el sujeto de la acción, toda vez que solo una entidad del Estado podría realizar esta conducta.

15 De acuerdo a esta disposición, la infracción al artículo $60^{\circ}$ de la Constitución se configura cuando una entidad pública (sea empresa estatal o no) realiza actividad empresarial sin contar con alguno de los requisitos establecidos en dicho artículo: autorización por ley expresa, subsidiariedad en la actividad realizada, alto interés público o manifiesta conveniencia nacional que justifique la actividad. Estos elementos han sido desarrollados en diversas resoluciones de Indecopi, en particular en la antes citada Resolución $N^{\circ}$ 31342010/SC1-Indecopi (Expediente № 201-2008/CCD, denuncia presentada por Pollería El Rancho II E.I.R.L. contra la Universidad del Altiplano - Puno). Esta línea de interpretación ha merecido comentarios variados, empezando por el voto en discordia de uno de los vocales de la sala. Diversos autores se han pronunciado sobre la resolución de Indecopi, tanto resaltándola como criticándola (un resumen de las opiniones vertidas sobre esta resolución y sus alcances se encuentra en Kresalja (2015) p. 157 a 180). En nuestra opinión, esta Resolución es importante en cuanto lleva a la luz la necesidad de debatir sobre los alcances de la actividad empresarial del Estado y la aplicación del artículo 14.3 del Decreto Legislativo $N^{\circ} 1044$, pero no establece una interpretación que haya sido aceptada pacíficamente por la doctrina. Otros casos que se han presentado posteriormente, como la denuncia sobre el arrendamiento del Estadio Nacional por el Instituto Peruano del Deporte (inclusive para eventos deportivos) o del Estadio de la Universidad Nacional Mayor de San Marcos, han planteado nuevas interrogantes sobre la aplicación de esta norma. 


\section{Gustavo Galván Pareja}

Kresalja (2005, p. 17), citando a Illescas ${ }^{16}$, nos explica que por ventaja significativa se entiende aquella que, en la generalidad de los casos, signifique una disminución en los costos o distribución de productos o servicios, y que por ese motivo el infractor obtiene "un diferencial de competitividad respecto de los restantes operadores, determinante de su acceso, permanencia o triunfo en el mercado, más allá de lo que en términos de competencia de prestación hubiera sido razonable esperar u obtener".

Este mismo autor se remite a José Massager para indicar que la ventaja, para ser significativa, debe tener "una magnitud apreciable"; por lo tanto, es preciso comprobar la desigualdad de la posición competitiva ${ }^{17}$.

No bastará, en consecuencia, que el actor de la conducta realice actos para valerse de alguna ventaja derivada de la concurrencia infringiendo normas. Se requiere que la ventaja sea significativa y ello debe ser demostrado. Si la LRCD no hubiese incorporado este requerimiento, se podría penalizar como "violación de normas" a cualquier actividad informal, sin que interese su importancia o magnitud, ni los efectos que pueda tener en la competencia.

En el caso de la actividad empresarial del Estado, el numeral 14.3 de la LRCD ha incorporado una presunción que excluye el análisis de los efectos que la conducta puede producir en la competencia. De este modo, si la transgresión del artículo $60^{\circ}$ de la Constitución no le concede a la entidad estatal ninguna ventaja ni su utilización genera efectos en el proceso competitivo, igualmente será sancionada.

Tratando sobre los efectos de la "violación de normas", recordemos que el numeral 14.1 de la LRCD indica que este acto debe tener "... como efecto, real o potencial, valerse en el mercado de una ventaja significativa". Por ello, si no existiera ventaja significativa, tampoco podría producirse el efecto (real o potencial) necesario para que exista la infracción.

16 Kresalja cita a Rafael Illescas: "La infracción inducida de contratos y de normas como acto de competencia desleal", en: Bercovitz, Alberto (Coord.), La regulación contra la competencia desleal en la ley de 10 de enero de 1991. Madrid: Cámara de Comercio e Industria. 1992, p. 116.

17 Kresalja (2005, p. 17) se refiere al texto de José Massager: Comentario a la ley de competencia desleal. Madrid: Civitas, 1999, p. 440. 


\section{Pensamiento Crítico Vol. ᄅl, № 2}

La importancia del efecto derivado del acto de competencia desleal no es privativa de la "violación de normas"; por el contrario, el efecto es necesario en todo acto de competencia desleal. Así lo señala el artículo $1^{\circ}$ de la LRCD:

"La presente Ley reprime todo acto o conducta de competencia desleal que tenga por efecto, real o potencial, afectar o impedir el adecuado funcionamiento del proceso competitivo".

De manera que, en el supuesto que analizamos, si la entidad del Estado tuviese una ventaja no significativa o no tuviese ninguna ventaja $y$, por ende, no se pudiera producir ningún efecto, real o potencial, que afecte o impida el proceso competitivo, aun así, se configuraría la infracción y se le podría sancionar.

Ello nos lleva a concluir que se ha incluido en la norma de competencia desleal una disposición que establece un tratamiento diferenciado para la actividad empresarial del Estado que no se encuentra justificada; toda vez que no se aprecia qué efecto negativo podría tener esta actividad respecto del proceso competitivo, si no se acredita previamente que la entidad o empresa estatal se esté valiendo de una ventaja significativa, como la norma exige para la generalidad de los casos.

La incorporación de este acápite específico para la actividad empresarial del Estado constituye un trato diferenciado no justificado hacia la actividad empresarial estatal que se aparta de la disposición constitucional que dispone que la "actividad empresarial pública o no pública recibe el mismo tratamiento legal".

No cabe duda de que la violación de una disposición constitucional amerita una sanción o el establecimiento de algún mecanismo o procedimiento que asegure su cumplimiento. Más aún si pensamos que las disposiciones constitucionales no son meras declaraciones, sino que deben aplicarse en la práctica. Sin embargo, ello no es un argumento válido para incluir en la norma de competencia desleal una disposición como la que comentamos, que conduce a penalizar una conducta que no tiene las características de un acto de "violación de normas"18.

18 Bullard (2011, p. 201), aun cuando felicita la inclusión del artículo 14.3 en las normas de competencia desleal, a fin de limitar y sancionar la actividad empresarial estatal no subsidiaria, también señala que se trata de una auténtica innovación peruana y que no conoce otro sistema legal que tenga algo parecido. 


\section{Gustavo Galván Pareja}

Es, sin duda, necesario desarrollar parámetros definidos que permitan facilitar o supervisar el cumplimiento del principio de subsidiariedad prescrito por la Constitución en lo que a la actividad empresarial del Estado se refiere; sin embargo, no resulta coherente asimilarlo a un supuesto de competencia desleal que no debe definirse por el autor de la infracción, sino por aspectos objetivos de la acción y por sus efectos en el proceso competitivo. En este caso, la norma general requiere que el infractor se valga de una ventaja significativa al momento de competir para que se produzca o pueda producir el efecto nocivo que la norma sanciona.

Tampoco encontramos suficiente el argumento genérico que señala que las empresas estatales siempre compiten deslealmente con el sector privado, porque pueden recurrir a recursos públicos para superar sus pérdidas económicas ${ }^{19}$. Más allá de que este argumento puede ser sometido a discusión, pues no toda actividad empresarial se desarrolla de la misma forma y bajo las mismas reglas, tampoco alcanzaría para sostener que la actividad empresarial no subsidiaria se adecúa a la descripción de un acto de "violación de normas" que tiene las características puntuales que ya hemos comentado.

Otro aspecto a tener en cuenta en nuestro análisis es la relación entre las disposiciones de la LRCD y el amplio alcance del concepto de subsidiariedad en la doctrina constitucional. El principio de subsidiariedad constitucional no se fundamenta en la necesidad de combatir la competencia desleal, sino en la inconveniencia de que la actividad estatal se desarrolle en ámbitos en los que es posible y preferible que se desarrolle la actividad privada. Por ello, la determinación de los límites de la actividad empresarial del Estado no debe reducirse a un análisis sobre la subsidiariedad económica -en términos de la competencia leal en el mercado- y dejar de lado el examen de la realidad en la que se desenvuelve esta actividad y de la diversidad de normas -muchas veces contradictorias- que la regulan.

El camino seguido para sancionar las infracciones al principio de subsidiariedad, creando una infracción en las normas de competencia desleal, ha obviado profundizar en el sentido de la subsidiariedad contenida en la Constitución y en el balance que debe realizarse respecto de las legítimas formas de intervención estatal y aquellas que no son deseables.

Una norma que regule los alcances del artículo $60^{\circ}$ de la Constitución requeriría un amplio debate que analice las diversas aristas de la actividad empresarial del Estado, lo cual no ocurrió en el caso de la LRCD, toda vez que fue emitida por el Poder Ejecutivo mediante un decreto legislativo.

19 En este sentido opinan Diez Canseco y Buleje (2011, p. 226), al explicar los distintos argumentos que justifican que se limite la actividad empresarial del Estado. 


\section{Pensamiento Crítico Vol. ᄅl, № 2}

\subsection{Otros casos de tratamiento legal diferenciado}

a) Expropiación y transferencia de inmuebles de propiedad del Estado

El numeral 41.1 del artículo 41 del Decreto Legislativo $N^{\circ} 1192$ - "Ley Marco de Adquisición y Expropiación de inmuebles, transferencia de inmuebles de propiedad del Estado, liberación de Interferencias y dicta otras medidas para la ejecución de obras de infraestructura" establece lo siguiente:

"Para la aplicación del presente Decreto Legislativo, los predios y/o edificaciones de propiedad estatal y de las empresas del Estado, requeridos para la ejecución de Obras de Infraestructura declaradas de necesidad pública, interés nacional, seguridad nacional y/o de gran envergadura, son transferidos a título gratuito y automáticamente al sector, gobierno regional o gobierno local o titular del proyecto al cual pertenece el proyecto, en la oportunidad que estos lo señalan y por el solo mérito de la resolución administrativa que emita la Superintendencia Nacional de Bienes Estatales (SBN), en un plazo máximo de cuarenta y cinco días hábiles contados desde la fecha de presentación de la solicitud. Esta resolución es irrecurrible en vía administrativa o judicial" (las negritas son nuestras).

La norma que comentamos se aprobó con el propósito de facilitar la ejecución de obras de infraestructura, aligerando los procedimientos necesarios para que la entidad que debía ejecutar la obra pudiese adquirir los inmuebles requeridos.

Bajo este régimen, una empresa estatal puede perder sus inmuebles si son necesarios para la ejecución de una obra de infraestructura declarada de necesidad pública, interés nacional, seguridad nacional y/o de gran envergadura, sin percibir nada a cambio.

En el caso de los inmuebles de propiedad privada, se aplica lo dispuesto por el artículo $70^{\circ}$ de la Constitución ${ }^{20}$ y se sigue el procedimiento de expropiación, detallado también en el Decreto Legislativo $N^{\circ} 1192$ que venimos comentando.

20 "Artículo $70^{\circ}$.- Inviolabilidad del derecho de propiedad (...) A nadie puede privarse de su propiedad sino, exclusivamente, por causa de seguridad nacional o necesidad pública, declarada por ley, y previo pago en efectivo de indemnización justipreciada que incluya compensación por el eventual perjuicio. Hay acción ante el Poder Judicial para contestar el valor de la propiedad que el Estado haya señalado en el procedimiento expropiatorio". 


\section{Gustavo Galván Pareja}

La diferencia entre el tratamiento que se da a los inmuebles de propiedad de las empresas del Estado y de las empresas privadas es clarísima: en el caso de una empresa estatal, se pierde el inmueble sin recibir compensación alguna; en el caso de una empresa privada, se sigue un procedimiento de expropiación y el propietario recibe una compensación económica (justiprecio) y un pago adicional por el perjuicio que pueda sufrir. De otro lado, si la empresa privada considera que el monto determinado como justiprecio es insuficiente, puede recurrir al Poder Judicial para que se revise y, eventualmente, se incremente el monto de la compensación.

En el caso de la empresa estatal, no solo la transferencia es "gratuita y automática", sino que además no cabe reclamo alguno en la vía administrativa o judicial.

A favor de la norma podría argumentarse que, tratándose de empresas estatales, el Estado es el propietario por lo que no cabe que se pague o indemnice a sí mismo. No obstante, se olvida que la empresa estatal debe funcionar con autonomía y perseguir objetivos de eficiencia (como hemos comentado previamente refiriéndonos al artículo $1^{\circ}$ del Decreto Legislativo $N^{\circ} 1031$ ), lo cual no es posible si en cualquier momento se le puede privar de sus bienes inmuebles sin ninguna compensación. En este caso, lo que ocurre es que la empresa estatal está siendo descapitalizada, por lo que de inmediato su situación patrimonial se ve afectada. Por las mismas razones, cualquier inversión o proyecto que la empresa pretenda realizar se torna azaroso y sumamente riesgoso, en la medida que puede frustrarse abruptamente por factores externos e imprevisibles: imaginemos que la empresa estatal ha contraído un crédito bancario para financiar un proyecto y luego pierde no solo el inmueble donde lo desarrollaba, sino también todo

lo invertido en él y, además, queda obligada a cumplir con los compromisos financieros adquiridos.

Por otro lado, no debemos olvidar que el Decreto Legislativo $\mathrm{N}^{\circ} 1031$ plantea un escenario de eventual participación privada minoritaria en las empresas estatales. Nos preguntamos: ¿bajo estas condiciones será posible que algún inversionista privado se interese en participar en el capital de la empresa estatal?, ¿no es un contrasentido que una ley promueva la incorporación de capital privado en la empresa estatal y otra norma indique que se le puede privar de su patrimonio en cualquier momento sin compensación alguna? 


\section{Pensamiento Crítico Vol. ᄅl, № 2}

A nuestro criterio, esta disposición del Decreto Legislativo $\mathrm{N}^{\circ} 1192$ debilita cualquier objetivo de procurar la eficiencia de la administración de las empresas estatales, pues las expone a riesgos imprevisibles. Por otro lado, conforme venimos comentando respecto de otras normas, se establece un tratamiento diferenciado entre la empresa estatal y la privada, sin suficiente justificación.

b) Obras por impuestos

La Ley $\mathrm{N}^{\circ} 29230$ "Ley que impulsa la inversión pública regional y local con participación del sector privado" se aprobó con el objeto de "...impulsar la ejecución de proyectos de inversión pública de impacto regional y local, con la participación del sector privado, mediante la suscripción de convenios con los gobiernos regionales y/o locales" (Artículo $1^{\circ}$ ).

La norma, también denominada ley de "obras por impuestos" -aludiendo al mecanismo que permite a la empresa privada descontar de sus tributos el monto aportado para la ejecución de las obras antes mencionadas-, se diseñó con el propósito de reducir la brecha de infraestructura de los gobiernos regionales y locales generada, entre otras razones, por las dificultades que ellos afrontaban para ejecutar inversiones ${ }^{21}$. En este contexto, la participación del sector privado en la inversión, junto con los gobiernos regionales y locales, fue considerada como un factor que facilitaría la ejecución de proyectos de estas entidades y ayudaría a incrementar el nivel de ejecución de obras de infraestructura. Posteriormente, el alcance del sistema fue ampliado a universidades públicas.

No quedaron explicitadas, en la exposición de motivos de los proyectos de ley ni en el dictamen de la Comisión de Economía, Banca, Finanzas e Inteligencia Financiera, las razones por las que no se consideró que las empresas del Estado pudieran participar

21 La exposición de motivos de los proyectos que originaron la Ley $\mathrm{N}^{\circ} 29230$ presenta el fundamento de las propuestas: Proyecto de Ley $\mathrm{N}^{\circ}$ 1398-2006-PE (Ley que impulsa la inversión pública regional y local con participación del sector privado) y Proyecto de Ley $\mathrm{N}^{\circ}$ 1572-2007-PE (Ley que promueve la inversión mediante la suscripción de convenios de cooperación con empresa privadas bajo la modalidad "construye y transfiere"). Ambos proyectos de ley se encuentran disponibles en el portal institucional del Congreso de la República http://www2.congreso.gob.pe/Sicr/TraDocEstProc/CLProLey2006.nsf. Puede consultarse también el Dictamen de la Comisión de Economía, Banca, Finanzas e Inteligencia Financiera en: http:// www2.congreso.gob.pe/Sicr/ApoyComisiones/dictamen20062011.nsf/DictamenesFuturo/97610B647AC 87CC2052573A9006759B8/\$FILE/1398_ECONOMIA_2007_2008.pdf 


\section{Gustavo Galván Pareja}

bajo esta modalidad de inversión en el desarrollo de infraestructura. Recordemos que las empresas del Estado tributan bajo las mismas reglas que las empresas privadas, por lo que podrían contribuir de igual forma a la ejecución de los proyectos.

Cabría agregar que la viabilidad de la participación de la empresa estatal se hace mayor si consideramos que el sistema de obras por impuestos no ha logrado un gran desarrollo. Albújar et al. (2016, p. 12) señalan que, desde su dación, la ley de obras por impuestos ha sufrido varios cambios y modificaciones, incluida la promulgación de un nuevo reglamento en enero del 2014 para perfeccionarla, “... sin embargo, desde que se promulgó no ha habido grandes avances en el número de obras realizadas. Según Pro Inversión, desde el 2009 hasta el 16 de agosto de 2014 el monto invertido en Obras por Impuestos ascendió a la suma de S/. 1263 millones en 103 proyectos adjudicados: 28 concluidos y 75 en proceso de ejecución".

El sistema de obras por impuestos, sin duda, plantea una propuesta positiva tanto para las entidades estatales beneficiarias como para las empresas participantes, por lo que su buen funcionamiento y desarrollo debe ser promovido. Por esta razón, no encontramos una explicación viable para que cualquier entidad pública o privada que pague tributos al Estado no pueda participar de este sistema.

En el caso de las empresas del Estado, la exclusión que establece la ley al referirse únicamente a las empresas privadas les impide participar en un sistema beneficioso para todos. Como señalan Albújar et al. (2016, p. 105), las empresas privadas que han participado del sistema refieren que el principal beneficio que pueden obtener es una mejora de las relaciones con la población. Es decir, la participación en este mecanismo es parte de su política de responsabilidad social empresarial. Igualmente afirman que "colateralmente, se llega a obtener un reflejo inmediato en la imagen institucional y una mejor relación con las entidades públicas, entre estas, los gobiernos regionales y locales y las universidades, además de una reputación pública más sólida y relaciones institucionales y de negocio mucho más rentables".

Estos resultados de desarrollo de comunidades, incremento de la inversión en obras de infraestructura y aplicación de prácticas de responsabilidad social empresarial pueden alcanzar un mayor desarrollo si se incluye a otros actores dispuestos a participar. 


\section{Pensamiento Crítico Vol. ᄅl, № 2}

\section{Comentarios finales}

La Constitución Política de 1993 introdujo el concepto de subsidiariedad en el desarrollo de la actividad empresarial del Estado y, a su vez, precisó que la actividad empresarial pública y no pública deben recibir igual tratamiento. De ahí que la legislación solo puede establecer restricciones a la actividad empresarial del Estado si existe una actuación no subsidiaria.

No obstante, hemos analizado tres disposiciones legales que establecen restricciones a la actividad empresarial del Estado por razones ajenas a la subsidiariedad y sin que se conozca o explique el soporte constitucional de este tipo de limitaciones.

Al referirnos a la normatividad sobre la actividad empresarial del Estado (Sección 2) indicamos que la orientación actual se dirige a la búsqueda de un desempeño eficiente y autónomo de la empresa estatal. Inclusive, en el caso de algunas empresas del Estado, las normas permiten incorporar capital privado minoritario. Sin embargo, la búsqueda de una administración eficiente y autónoma encontrará serias dificultades si existe la posibilidad de que se establezcan restricciones no justificadas o de que se afecte su patrimonio sin compensación. En este escenario será también improbable que algún accionista privado pueda interesarse en adquirir una participación en una empresa del Estado.

Por otra parte, en nuestro sistema jurídico existe normatividad que permite, facilita o promueve que las empresas y otras entidades del Estado realicen actividad empresarial. En estos casos, la actividad de la empresa se orienta a alcanzar los fines del Estado en general o de alguna entidad pública en particular. Estos supuestos, si bien no son incompatibles con la subsidiariedad, en la práctica pueden subordinarla a alcanzar los fines que el Estado persigue.

El análisis de la subsidiariedad de la actividad empresarial del Estado no debe realizarse solamente en función de la competencia en el mercado (tal como ocurre con las normas de competencia desleal), sino que debe cubrir un espectro más amplio que permita evaluar la pertinencia de la actividad empresarial como instrumento para que el Estado alcance los fines que la Constitución le asigna. El análisis de las complejas circunstancias en que se desarrolla la actividad empresarial del Estado y de las tensiones existentes entre las normas que la habilitan y aquellas que pretenden restringirla debe ser un punto de partida para avanzar en el debate inconcluso sobre el papel que le cabe desempeñar a la actividad empresarial del Estado. 


\section{Gustavo Galván Pareja}

\section{Referencias bibliográficas}

Albújar, A., Santa Cruz, E., Albújar, J., Gómez, I., Quezada, K. y Terrones, S. (2016). Obras por Impuestos: factores que promueven la participación de la empresa privada - Lima: Universidad ESAN. Disponible en: http://www.esan.edu.pe/ publicaciones/2016/04/12/Obras\%20por\%20impuestos.pdf

Ariño, G. (2004). Principios de Derecho Público Económico (Modelo de Estado, Gestión Pública, Regulación Económica) Granada: Comares.

Bullard, A. (2011). El otro pollo. La competencia desleal del Estado por violación del principio de subsidiariedad. Revista de Derecho Administrativo No 10 , Tomo II, pp. 199-209.

Diez Canseco, L. y Buleje, C. (2011). Analizando el papel Subsidiario del Estado a propósito de la Resolución No 3134-2010/CS1-INDECOPI. Revista de Derecho Administrativo No 10, Tomo II, pp. 221-235.

García, V. (1998). Análisis sistemático de la Constitución peruana de 1993. Tomo II. Lima: Universidad de Lima.

Kresalja, B. (2015).¿Estado o mercado? El principio de subsidiariedad en la Constitución Peruana. Lima: Pontificia Universidad Católica del Perú.

Kresalja, B. (2005). Lo que a mí no me está permitido hacer tampoco debe permitírsete a ti (Apuntes sobre el acto desleal por violación de normas). Thémis $\mathrm{N}^{\circ}$ 50: 7-31.

Kresalja, B. y Ochoa, C. (2009). Derecho Constitucional Económico. Lima: Pontificia Universidad Católica del Perú.

Resolución N 3134-2010/SC1-INDECOPI. Consultar en:http://servicio.indecopi.gob. pe/buscadorResoluciones/tribunal.seam

Sentencia del Tribunal Constitucional de fecha 11 de noviembre de 2003 (Exp. $\mathrm{N}^{\circ}$ 0008-2003-AI/TC). Disponible en:http://www.tc.gob.pe/jurisprudencia/2003/000082003-AI.html 